no fewer than 60 started to lay down fat early in pregnancy and all save two of them were prevented from laying down more unnecessary fat without any calorie control whatever, merely by cutting out sugar and sweet items of food and reducing the intake of products made from white flour. ${ }^{3}$ The average weight gain of the series, excluding toxaemic patients, was $10.0 \mathrm{~kg}(21.9 \mathrm{lb})$ as against the average uncontrolled weigh gain in recent British series of $12.5 \mathrm{~kg}$ $(27.5 \mathrm{lb})$, which Hytten and Leitch, ${ }^{4}$ from the Aberdeen team, estimate to include 3.5 $\mathrm{kg}(7.7 \mathrm{lb})$ of fat. Moreover 30 of my patients who were followed through a second pregnancy ${ }^{5}$ put on no weight between pregnancies on average, and women who have been under my antenatal care have no overweight children in their families, so that their children have also learnt to eat wisely.

Women, as a rule, do not like putting on weight. What weight is lost between pregnancies is not usually achieved "without conscious effort" in my opinion, and most women would prefer to prevent excess weight gain during pregnancy to having to cope with dieting while looking after a tiny baby. The teaching of healthy eating habits during pregnancy seems to me to be the most important positive action which doctors can take to prevent obesity and other diseases produced by our excessive intake of sugar and other refined foods.-I am, etc.,

\section{South Croydon}

DENIS CRADDOCK 1 Billewicz, W. Z., and Thomson, A. M., British 24, 97.

Scotch, N., Sampel, B., Abramson, J. M. M., and
Scoth Medical fournal, 1960

Craddock, D., Obesity and its Management, 2nd Hytten, F. E., and Leitch I. The Physio'ogy. Human Pregnancy, 2nd edn. Oxford, Blackwell, 1971 . Craddock, D., Fournal of Obstetrics and Gynae-
cology of the British Commonwealth, 1970, 77,
728.

\section{Plasma Digoxin Concentration in Children with Heart Failure}

SIR,-We thank Professor V. Dubowitz (14 April, p. 118) for his interest in our paper (24 February, p. 443) and would like to answer the important points he raises.

Our purpose was to present the plasma digoxin concentrations measured during satisfactory maintenance therapy of infants and children with cardiac failure. We agree that plasma levels achieved during initial digitalization should be measured in order to determine the optimum digitalizing dose. This would require several samples of blood, and when we conducted our study $1.5 \mathrm{ml}$ of plasma was necessary for each radioimmunoassay. We have now evolved a microassay requiring only $0 \cdot 1-0.3 \mathrm{ml}$ of plasma and are using this to determine the necessary digitalization dose in infants and children.

All our reported patients had moderate to severe cardiac failure with the clinical signs of tachycardia, tachypnoea, and hepatomegaly; some had pulmonary and peripheral oedema. An improvement in all these signs was indicative of a satisfactory clinical response.

Even in the presence of severe heart failure the oral maintenance dose was absorbed sufficiently to give plasma levels com- parable to therapeutic adult levels. If oral or intragastric administration is not tolerated, it is our practice to give half the oral dose by the intramuscular route, but to date we have no measurement of the resulting plasma levels. The development of a microassay of digoxin will facilitate further studies of the infant's handling of this drug. -We are, etc.,

Royal Alexandra Hospital,

Jean E. Cree

tanford University Medical Center,

D. John Coltart

Stanford, California

\section{Neonatal Renal Tumours}

SIR,-At the end of your leading article entitled "Early Diagnosis of Nephroblastoma" (10 March, p. 567) you identify the small group of neonatal tumours for which you say that fibrosarcoma is an acceptable term. However, this is totally misleading in this context, as hinted at by $\mathrm{Mr}$. R. B. Zachary and Dr. F. Harris (24 April, p. 179). Not only is there considerable doubt as to whether these tumours are totally of fibroblastic origin, ${ }^{1-3}$ though this may be a component, but, as you point out, there is no recorded instance of any child developing metastases from these tumours. There is therefore no evidence to justify the term sarcoma being applied to them. Also, in most cases they show none of the histological criteria of malignancy, though the occasional case does arise, such as that described by Fraser, ${ }^{4}$ in which the distinction from an undifferentiated Wilms's tumour may be difficult, though even this had not metastasized when described.

While there is some doubt as to the true nature of these mesenchymal tumours, as exemplified by such terms as congenital mesoblastic or mesonephric nephroma, ${ }^{1-3}$ they certainly also conform to the criteria of hamartoma as suggested by Willis. ${ }^{5}$ The title fetal hamartoma of the kidney, as used by Wigger, ${ }^{2}$ bears the virtues of simplicity and probable accuracy. Nevertheless, fibrosarcomas they are not, and this term should surely not be used to describe these tumours. -I am, etc.,

Department of Pathology,

St. Bartholomew's Hospital

R. H. RIDDELL

Favara. B. E., Johnson, W., and Ito, J., Cancer, Wigman, H. J., American fournal of Clinical Pathology, 1969, 51, 323.

Pediatrics, P., Brough, A. J., and Izant, R. J., Fraser, G. C., British fournal of Urology, 1967,

illis, R. A., The Borderline of Embryology and Pathology, 2nd edn. London, Butterworth, 1962.

\section{Is Your Pain Really Necessary?}

SIR,-In your leading article (12 May, p. 323) you refer to the common assumption that primary dysmenorrhoea is "necessarily psychogenic" as invalid since "suppression of ovulation nearly always relieves it." I have evidence that to label such pain as psychogenic may well be a misdiagnosis.

In the treatment of infertility, in large numbers of apparently healthy women no apparent cause can be found, but quite often there is a significant history of dysmenorrhoea, sometimes of abrupt onset in late adolescence. In some of these women a hysterosalpingogram has shown significant impairment of tubal function, and some years ago I began to ask my gynaecological colleagues to laparoscope these women. Endometriosis has been found, sometimes perhaps as small a plaque as 3-4 $\mathrm{mm}$ diameter, but in a situation where it could cause interference with tubal transport but not be visible by salpingography. Very recently I have begun to refer patients with apparently normal $x$-rays and sometimes without dysmenorrhoea, and again significant endometriosis has been found by laparoscopy. These women have come from different town and have been treated by different gynaecologists, and one cannot therefore say that they are a selection of Manchester women only.

The use of early laparoscopy has thus rescued many women not only from the diagnosis of psychogenic pain and completely cured their pain, at the same time curing their infertility, but also possibly prevented a hysterectomy later. It would seem that we are not perhaps justified in withholding laparoscopy from young women complaining of severe dysmenorrhoea.-I am, etc.,

BERNARD SANDLER Manchester Victoria Memorial Jewish Hospital,
Manchester

\section{Treatment of Dextropropoxyphene Poisoning}

SIR,-We were interested to read Dr. Vanessa Hunt's report of a case of dextropropoxyphene poisoning successfully treated by nalorphine (3 March, p. 554). We too have had success with nalorphine in this type of poisoning. More recently, however, we have successfully treated a patient with severe dextropropoxyphene poisoning (taken as Distalgesic) with the new narcotic antagonist naloxone (Narcan).

A 32-year-old woman was admitted to the Regional Poisoning Treatment Centre in grade 3 coma, ${ }^{1}$ having been found unconscious in the street. Clinical examination revealed markedly constricted pupils a respiratory rate of $2 / \mathrm{min}$, and hypotension. Within one minute of receiving $0.8 \mathrm{mg}$ of naloxone intravenously her pupils dilated, the respiratory rate rose to $20 / \mathrm{min}$, and she regained consciousness. She subsequently required one further intramuscular dose a few hours later. As with nalorphine the effect of naloxone may be shortlasting and in the individual patients further dosage has to be tailored to sustain a satisfactory respiratory rate.

The clinical uses and effects of naloxone have recently been reported by Evans et al.,2 whose series, however, did not include dextropropoxyphene poisoning. We can now report that overdosage with this drug can be effectively treated with naloxone and we know of no such previously reported case. In addition, we have found that intravenous naloxone will rapidly terminate apomorphineinduced emesis without any untoward effects. Naloxone was supplied to us by Endo Laboratories, Inc., U.S.A., but at present is not commercially available in Britain.-We are, etc.,

RICHARD TARALA

Royal Infirmary, JOHN A. H. FORREST

Edinburgh Matthew, H., and Lawson, A. A. H., Treatment
of Common Acute Poisonines, 2nd edn. London Evans, L. E. J., Roscoe, P., Swainson.C. P., and 